\title{
Polymorphisms in Pvkelch 12 and gene amplification of Pvplasmepsin4 in Plasmodium vivax from Thailand, Lao PDR and Cambodia
}

Jureeporn Duanguppama 1,2, Vivek Bhakta Mathema', Rupam Tripura², Nicholas P. J. Day²,3, Mayfong Maxay ${ }^{5,6}$, Chea Nguon7, Lorenz von Seidlein², Mehul Dhorda², Thomas J. Peto ${ }^{2}$, Francois Nosten ${ }^{2,3,4}$, Nicholas J. White ${ }^{2,3}$, Arjen M. Dondorp ${ }^{2,3}$ and Mallika Imwong ${ }^{1,2^{*}}$

\begin{abstract}
Background: Mutations in Pfkelch13 and Pfplasmepsin2/3 gene amplification are well-established markers for artemisinin and piperaquine resistance in Plasmodium falciparum, a widespread problem in the Greater Mekong Subregion (GMS). The Plasmodium vivax parasite population has experienced varying drug pressure dependent on local drug policies. We investigated the correlation between drug pressure from artemisinins and piperaquine and mutations in the P. vivax orthologous genes Pvkelch12 and Pvplasmepsin4 (Pvpm4), as candidate resistance markers.

Methods: Blood samples from 734 P. vivax patients were obtained from Thailand $(n=399)$, Lao PDR $(n=296)$ and Cambodia ( $n=39$ ) between 2007 and 2017. Pvkelch12 and Pvpm4 was amplified and sequenced to assess gene mutations. To assess PVPM4 gene amplification, a Taqman ${ }^{\circledR}$ Real-Time PCR method was developed and validated. Selection of non-synonymous mutations was assessed by its ratio with synonymous mutations (Ka/Ks ratios). Mutation rates were compared to the estimated local drug pressure.

Results: Polymorphisms in Pvkelch12 were rare. Pvkelch 12 mutations V552I, K151Q and M124I were observed in 1.0\% (7/734) of P. vivax samples. V552I was the most common mutation with a frequency of $0.7 \%$ (5/734), most of which (4/5) observed in Ubon Ratchathani, Thailand. Polymorphisms in Pvpm4 were more common, with a frequency of 40.3\% (123/305) in 305 samples from Thailand, Lao PDR and Cambodia, but this was not related to the estimated piperaquine drug pressure in these areas (Pearson's $x^{2}$ test, $p=0.50$ ). Pvpm 4 mutation V165I was most frequent in Tak, Thailand (40.2\%, 43/107) followed by Pailin, Cambodia (43.5\%, 37/85), Champasak, Lao PDR (40.4\%, 23/57) and Ubon Ratchathani, Thailand (35.7\%, 20/56). Pvpm4 amplification was not observed in 141 samples from Thailand and Cambodia. For both Pvkelch 12 and Pvpm4, in all areas and at all time points, the Ka/Ks values were $<1$, suggesting no purifying selection.

Conclusions: A novel real-time PCR-based method to assess P. vivax Pvpm4 gene amplification was developed. Drug pressure with artemisinins and piperaquine in the GMS was not clearly related to signatures of selection for mutations in the P. vivax orthologous resistance genes Pvkelch 12 and Pvpm4 in areas under investigation. Current resistance of $P$. vivax to these drugs is unlikely and additional observations including analysis of associated clinical data from these regions could further clarify current findings.
\end{abstract}

Keywords: Drug pressure, SNPs, P. vivax, CNV, Malaria, Mutations

\footnotetext{
*Correspondence: noi@tropmedres.ac

${ }^{1}$ Department of Molecular Tropical Medicine and Genetics, Faculty

of Tropical Medicine, Mahidol University, Bangkok, Thailand

Full list of author information is available at the end of the article
} 


\section{Background}

Anti-malarial drug resistance is a threat for the elimination of falciparum malaria in the Greater Mekong Subregion (GMS) which includes Cambodia, Lao PDR, Myanmar, Thailand, and Vietnam [1]. For over a decade artemisinin-based combination therapy (ACT) has been the first-line treatment for uncomplicated Plasmodium falciparum malaria [2]. The artemisinin-based combinations deployed in the GMS since 2001 include artesunate-mefloquine (AS-MQ), dihydroartemisininpiperaquine (DHA-PPQ) and artemether-lumefantrine (AL). Cambodia was the first country to deploy AS-MQ in 2000. Treatment failure in falciparum malaria was first reported 4 years later in 2004 [3]. DHA-PPQ was introduced in Cambodia in 2003 and treatment failure was first reported in 2010 [4]. Thailand started implementation of AS-MQ in 1990 and first reported increased treatment failure in 2010. DHA-PPQ was more recently introduced in Thailand and increased treatment failure was recently observed in a northeastern province close to the Cambodian border in 20152016 (unpublished). Countries were stratified according to their first-line treatments for P. vivax (chloroquine in Lao PDR and Thailand; ASMQ+ primaquine in Cambodia), as well as according to the first-line treatment for P. falciparum (AL in Lao PDR, DHA-PPQ in Thailand, ASMQ in Cambodia) [1].

Compared to $P$. falciparum, $P$. vivax is geographically the most widespread human malaria with over 2.5 billion people living at risk of infection [5]. Vivax malaria has a high prevalence in South-East Asia, Western Pacific regions, and Central and South America [6-8]. In the GMS the proportion of $P$. vivax and $P$. falciparum cases are estimated as $34 \%$ and $66 \%$, respectively [1]. In addition to clinical cases, prevalence of $P$. vivax in asymptomatic parasite carriers, as assessed by PCR methods, is also high, with an average of $30 \%$ [9]. In Lao PDR, mixed infections of $P$. vivax and $P$. falciparum account for up to $6.5 \%$ of clinical malaria cases [10]. Therefore, the P. vivax population will be exposed to ACT used for treatment of falciparum malaria, even where chloroquine is still the first-line drug for $P$. vivax treatment [1]. Drug pressure from ACT on the P. vivax parasite population is higher in Cambodia where ACT is the first-line treatment for P. vivax.

Single Nucleotide Polymorphisms (SNPs) at multiple loci in the propeller region of the P. falciparum kelch (Pfkelch13) gene are the main genetic marker for artemisinin resistance and have reached high frequencies in most countries of the GMS. Examples are the nonsynonymous mutations in Pfkelch13; C580Y, R539T and $\mathrm{Y} 439 \mathrm{H}$, with $\mathrm{C} 580 \mathrm{Y}$ over time becoming the most dominant mutation [11-15]. The orthologous gene for Pfkelch13 in P. vivax (Pvkelch12) has been identified and mapped onto chromosome 12 (accession number PVX_083080, kelch12 propeller) with a nucleotide and protein sequence length of $2139 \mathrm{bp}$ and 712 amino acids, respectively (Fig. 1). Few Pvkelch12-associated nonsynonymous mutations have been identified in $P$. vivax isolates in Cambodia [16]. In addition to artemisinin resistance, countries in the GMS have witnessed more recently the emergence and spread of piperaquine resistant $P$. falciparum. Gene amplification of the $P$. falciparum plasmepsin 2 and 3 genes (Pfplasmepsin $2 / 3$ ) has been identified as a marker for piperaquine resistance $[3,17$, 18]. The orthologous gene for Pfplasmepsin $2 / 3$ in $P$. vivax is $P$. vivax plasmepsin4 (Pvpm4), identified and mapped for $P$. vivax reference strain Sal-1 located on chromosome 13 (accession number PVX_086040). It has a sequence length of $1353 \mathrm{bp}$ and codes for a 450 amino acids protein [16]. Recently genetic variation in Pvpm4 has been reported from Malaysia, Thailand and Indonesia, in particular the nonsynonymous mutation Pvplasmepsin4 I165V [19]. There is no information on copy number variation (CNV) in Pvpm4 in P. vivax field isolates.

In the current study, gene polymorphisms in Pvkelch12 and Pvpm4 were accessed in P. vivax field isolates from three countries of the GMS (Thailand, Lao PDR and Cambodia), and related this to the estimated drug pressure on the parasite population. For this, a real-time PCR method was developed and optimized for Pvpm4 CNV analysis in field isolates.

\section{Methods}

Study sites and sample collection

Whole blood samples from both clinical cases and asymptomatic carriers of $P$. vivax were obtained in

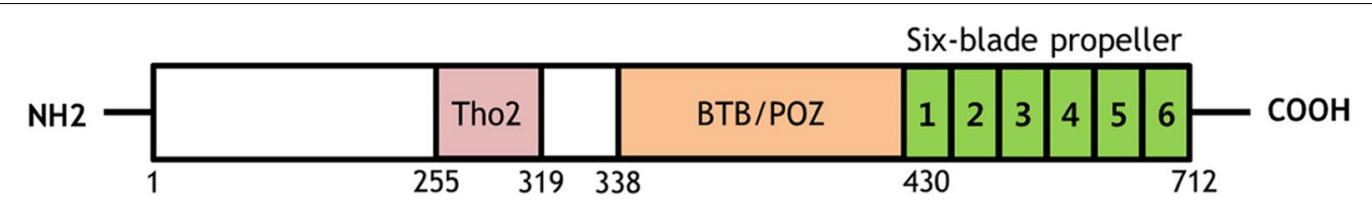

Fig. 1 Schematic representation of Pvkelch 12 gene. The Pvkelch 12 is located on chromosome 12 with nucleotide sequence length of 2139 bp which codes for 712 amino acids. The gene itself has been predicted to consist of three domains: Tho2 super family (65 bp), BTB/POZ (93 bp) and Six-blade propeller (283 bp) 
Thailand (Ubon Ratchathani and Tak), Lao PDR (Champasak, Savannakhet, Xekong and Salavan) and Cambodia (Pailin) between 2007 and 2017. Genomic DNA was extracted from whole blood by using QIAamp ${ }^{\circledR}$ DNA Blood Mini Kit (Qiagen, Germany) and purified DNA was stored at $-20{ }^{\circ} \mathrm{C}$ until further use. The study was approved by the Ethics Committee of Faculty of Tropical Medicine, Mahidol University, Thailand (EC approval number MUTM 2017-037-01).

\section{Amplification and sequencing of Pvkelch12 and Pvpm4}

Primers designed for Pvkelch12 and Pvpm4 genes were based on the $P$. vivax Sal-1 genome (Table 1). DNA of the Pvkelch 12 and Pvpm4 genes was amplified by seminested PCR (Table 1). For PCR amplification the primary and secondary reaction volumes were 25 and $100 \mu \mathrm{l}$, respectively. The amplified PCR products were further purified by using PCR purification kit, FavorPrep ${ }^{\mathrm{TM}}$ (Favorgen, Taiwan), following standard manufacturer's instructions. The specificity of all primer pairs designed for this study was tested against both human and nonhuman primate Plasmodium species, and no cross-reactivity was observed with non-P. vivax species, to exclude cross-species contamination of PCR products. The nucleotide sequences of Pvkelch12 and Pvpm4 genes obtained in this study have been submitted to GenBank database under the accession numbers MK513662-MK513680 and MK513681-MK513709, respectively (Additional file 1).

\section{DNA sequence analysis}

Purified products from the secondary PCR were subjected to DNA sequencing (Macrogen, Korea). Gene sequences of the PCR amplification products of Pvkelch12 (accession number: XM_001614165.1, Sal-1; PVX_083080) and Pvpm4 (accession number: XM_001616821.1, Sal-1; PVX_086040) were confirmed using the NCBI's Blastn and Blastx programs. Subsequently, gene polymorphisms were assessed by comparison with the reference sequences using BioEdit v7.2.5.

\section{Identification of signature of selection}

The ratio of nonsynonymous site (Ka) to synonymous single nucleotide polymorphisms (Ks) or $\mathrm{Ka} / \mathrm{Ks}$ ratios was assessed to identify signatures of gene selection in the parasite population, using the online available $\mathrm{Ka} /$ Ks Calculator (https://kakscalculator.herokuapp.com/ calculate.action). This provides the Jukes-Cantor (JC) and Kimuras-two parameters (K2P) as measures of purifying selection [20,21]. Differences in categorical variables were examined using Pearson's Chi squared test.

\section{Development of real-time PCR to assess Pvpm 4 copy number variation (CNV)}

A method to assess Pvpm4 $\mathrm{CNV}$ was developed. For this specific primers for Pvpm4 and Pv $\beta$-tubulin (internal control in the real-time PCR reaction) were designed based on the P. vivax Sal-1 (PVX_086040) reference gene (Table 1). BLAST analysis of amplified fragments showed a high alignment score of $99 \%$ for Pvpm4 and $91 \%$ for Pv $\beta$-tubulin sequence identity compared to the reference $P$. vivax Sal-1 genome. The regions identified for PCR amplification were highly conserved and specific for P. vivax. Primers were labelled with 6-carboxyfluorescein (6-FAM) and 6-carboxytetramethyl-rhodamine (TAMRA) as quencher. CNV was assessed by QuantiTect multiplex PCR NoRox kits (Qiagen, Germany) following standard manufacturer's instructions. Pvpm4 plasmids with one and two copy numbers were used as calibrators and positive controls. These plasmids were prepared by cloning of plasmid vectors following standard manufacturer's instructions (pGEM ${ }^{\circledR}$-T Easy Vector Systems, Promega, USA). Each PCR reaction contained a total volume of $10 \mu \mathrm{l}$ including $2 \mu \mathrm{l}$ of genomic DNA as the template. PCR master mix was prepared using $1 \times$ QuantiTect Multiplex (NoRox), $0.4 \mu \mathrm{M}$ of both forward and reverse primers, and $0.2 \mu \mathrm{M}$ of TaqMan probe and RNase-free water. The thermocycler (Rotor-Gene Q 5plex System, QIAGEN) profile was: initial denaturation at $95^{\circ} \mathrm{C}$ for $15 \mathrm{~min}$, 50 cycles of denaturation at $95^{\circ} \mathrm{C}$ for $15 \mathrm{~s}$ followed by annealing at $58^{\circ} \mathrm{C}$ for $1 \mathrm{~min}$, and final extension at $72{ }^{\circ} \mathrm{C}$ for $5 \mathrm{~min}$. The detection threshold cycle $(\mathrm{Ct})$ was calculated by using the $2^{-\Delta \Delta \mathrm{CT}}$ method where, $\Delta \Delta \mathrm{Ct}=(\mathrm{Ct}$ of Pvpm4-Ct of Pv/-tubulin) of sample-(Ct of Pvpm4-Ct of $P v \beta$-tubulin) of Pvpm4 plasmid clone. The specificity of the real-time PCR method was validated using isolated human DNA from healthy subjects $(\mathrm{n}=50)$, patients with $P$. falciparum $(\mathrm{n}=50)$ and $P$. vivax $(\mathrm{n}=50)$. This confirmed that the used primers were highly specific to $P$. vivax without any undesired amplification of host DNA or P. falciparum DNA. Pvpm4 gene amplification (2 or more) was called when $2^{-\Delta \Delta \mathrm{Ct}}$ exceeded 1.5 , with a $\mathrm{Ct}$ value acquired after less than 35 cycles.

\section{Results}

\section{Polymorphisms in Pvkelch12 and Pvpm4}

Analysis of Pvkelch12 in P. vivax strains from Thailand, Lao PDR and Cambodia showed nonsynonymous mutations as $1.0 \%(7 / 734)$ of samples, at codons Val552Ile (V552I), Lys151Gln (K151Q) and Met124Ile (M124I). The V552I mutation was most frequent, followed by K151Q and M124I. V552I has an overall prevalence of $0.7 \%$ (5/734) and was observed in Ubon Ratchathani, Thailand $(1.4 \%, 4 / 286)$ and Champasak, Lao PDR $(0.3 \%$, 
Table 1 Sequence specific oligonucleotide primers, probes and temperature profiles for Pvkelch12 and Pvpm4 genes

\begin{tabular}{|c|c|c|c|c|c|c|c|c|}
\hline \multirow[t]{2}{*}{ Gene } & \multirow[t]{2}{*}{ Method } & \multirow[t]{2}{*}{ Fragment } & \multirow[t]{2}{*}{ Primer name } & \multirow[t]{2}{*}{ Sequence $\left(5^{\prime}-3^{\prime}\right)$} & \multicolumn{4}{|l|}{ PCR condition } \\
\hline & & & & & $\begin{array}{l}\text { Annealing } \\
\text { Temperature } \\
\left({ }^{\circ} \mathrm{C}\right)\end{array}$ & $\mathrm{MgCl}_{2}(\mathrm{mM})$ & $\begin{array}{l}\text { No. } \\
\text { of PCR } \\
\text { cycle }\end{array}$ & $\begin{array}{l}\text { Estimated PCR } \\
\text { product Size } \\
\text { (bp) }\end{array}$ \\
\hline \multirow[t]{8}{*}{ Pvkelch12 } & \multirow[t]{8}{*}{$P C R$} & \multirow[t]{2}{*}{ Nest 1} & K12_F1-F & $\begin{array}{l}\text { CCATACGTAAACGCT } \\
\text { GCAAAT }\end{array}$ & \multirow[t]{2}{*}{58} & \multirow[t]{2}{*}{2} & \multirow[t]{2}{*}{25} & \multirow[t]{2}{*}{2139} \\
\hline & & & K12_c.2216R & $\begin{array}{l}\text { CTCCCCATCTGTTCC } \\
\text { ATGTC }\end{array}$ & & & & \\
\hline & & \multirow[t]{2}{*}{$\mathrm{F} 1$} & K12_F1-F & $\begin{array}{l}\text { CCATACGTAAACGCT } \\
\text { GCAAAT }\end{array}$ & \multirow[t]{2}{*}{58} & \multirow[t]{2}{*}{2} & \multirow[t]{2}{*}{30} & \multirow[t]{2}{*}{980} \\
\hline & & & K12_F1-R* & $\begin{array}{l}\text { TTCTTAATTTGTTTATAC } \\
\text { CCGTTTGA }\end{array}$ & & & & \\
\hline & & \multirow[t]{2}{*}{ F2 } & K12_F2-F & $\begin{array}{l}\text { CAAGCTTTTTAAAGACAA } \\
\text { AAAGGAA }\end{array}$ & \multirow[t]{2}{*}{58} & \multirow[t]{2}{*}{2} & \multirow[t]{2}{*}{30} & \multirow[t]{2}{*}{728} \\
\hline & & & K12_F2-R* & $\begin{array}{l}\text { CAGTTTCGAAAAGGG } \\
\text { CTTTATAATC }\end{array}$ & & & & \\
\hline & & \multirow[t]{2}{*}{ F3 } & K12_c.1304F* & $\begin{array}{l}\text { TGGTTTCGATGGGGT } \\
\text { AGAGT }\end{array}$ & \multirow[t]{2}{*}{58} & \multirow[t]{2}{*}{2} & \multirow[t]{2}{*}{30} & \multirow[t]{2}{*}{912} \\
\hline & & & K12_c.2216R & $\begin{array}{l}\text { CTCCCCATCTGTTCC } \\
\text { ATGTC }\end{array}$ & & & & \\
\hline \multirow[t]{6}{*}{ Pvpm4 } & \multirow[t]{6}{*}{ PCR } & \multirow[t]{2}{*}{ Nest 1} & PV_PM4F1_F & $\begin{array}{l}\text { TCAAAAGGAGTACGA } \\
\text { AGCATACAA }\end{array}$ & \multirow[t]{2}{*}{62} & \multirow[t]{2}{*}{2} & \multirow[t]{2}{*}{30} & 1703 \\
\hline & & & PV_PM4F2_R & $\begin{array}{l}\text { TGTTCTAATTACAGCACC } \\
\text { AACACA }\end{array}$ & & & & \\
\hline & & F1 & PV_PM4F1_F* & $\begin{array}{l}\text { TCAAAAGGAGTACGA } \\
\text { AGCATACAA }\end{array}$ & 62 & 2 & 30 & 807 \\
\hline & & & PV_PM4F1_R* & $\begin{array}{l}\text { ATGGGTTCTAAATCATCA } \\
\text { GTGTCA }\end{array}$ & & & & \\
\hline & & $F 2$ & PV_PM4F2_F* & $\begin{array}{l}\text { GATGCAGCATTAAAAATC } \\
\text { TGTACG }\end{array}$ & 62 & 2 & 30 & 1086 \\
\hline & & & PV_PM4F2_R & $\begin{array}{l}\text { TGTTCTAATTACAGCACC } \\
\text { AACACA }\end{array}$ & & & & \\
\hline Pvpm4 & $\begin{array}{l}\text { Vector- } \\
\text { based } \\
\text { primer }\end{array}$ & Pvpm4 & $\begin{array}{l}\text { CPvPM4-F* } \\
\text { CPvPM4-R* }\end{array}$ & $\begin{array}{l}\text { AAAATCGAGAGACCCTAT } \\
\text { GACAAG } \\
\text { ATGGGTTCTAAATCATCA } \\
\text { GTGTCA }\end{array}$ & 62 & 2 & 35 & 461 \\
\hline & & Pv $\beta$-tubulin & CPvtubulin-F* & $\begin{array}{l}\text { AAATTAGGGAAGAATACC } \\
\text { CAGACC }\end{array}$ & 62 & 2 & 35 & 451 \\
\hline & & & CPvtubulin- $R^{*}$ & $\begin{array}{l}\text { TCACTTGCACACATCATA } \\
\text { TTCTTG }\end{array}$ & & & & \\
\hline Pvpm4 & $\begin{array}{l}\text { Real-time } \\
\text { PCR }\end{array}$ & Pvpm4 & $\begin{array}{l}\text { Pvpm4_F(CNV) } \\
\text { Pvpm4_R(CNV) } \\
\text { PvPm4_Probe(CNV) }\end{array}$ & $\begin{array}{l}\text { ACCACCAAAAGTTTATGC } \\
\text { TCATC } \\
\text { CGTAAGACTTAGACTTGC } \\
\text { TAGAGTCG } \\
\text { 6FAM-CAAAAAATGCAA } \\
\text { TAGCAGCGGA-TAMRA }\end{array}$ & 58 & - & 50 & 133 \\
\hline & & Pv $\beta$-tubulin & $\begin{array}{l}\text { PvTubulin_F(CNV) } \\
\text { PvTubulin_R2(CNV) } \\
\text { PvTubulin_Probe(CNV) }\end{array}$ & $\begin{array}{l}\text { GATAATGAGGCCTTGTAT } \\
\text { GATATTT } \\
\text { AGGAAATCTTAACGAACA } \\
\text { TGTAACT } \\
\text { HEX-TGGTTTCTGCTGCCA } \\
\text { TGTCAGG-TAMRA }\end{array}$ & 58 & - & 50 & 123 \\
\hline
\end{tabular}

1/296). The K151Q and M124I mutations were only observed in Tak, Thailand $(0.9 \%, 1 / 113$ and $0.9 \%, 1 / 113)$ (Fig. 2). Assessment of Pvpm4 showed nonsynonymous mutation in $40.3 \%(123 / 305)$ of samples, with Val165Ile
(V165I), mostly observed in Pailin, Cambodia (43.5\%, 37/85) followed by Champasak, Lao PDR (40.4\%, 23/57), Tak, Thailand $(40.2 \%, 43 / 107)$ and Ubon Ratchathani, Thailand (35.7\%, 20/56) (Fig. 3). The observed mutation 


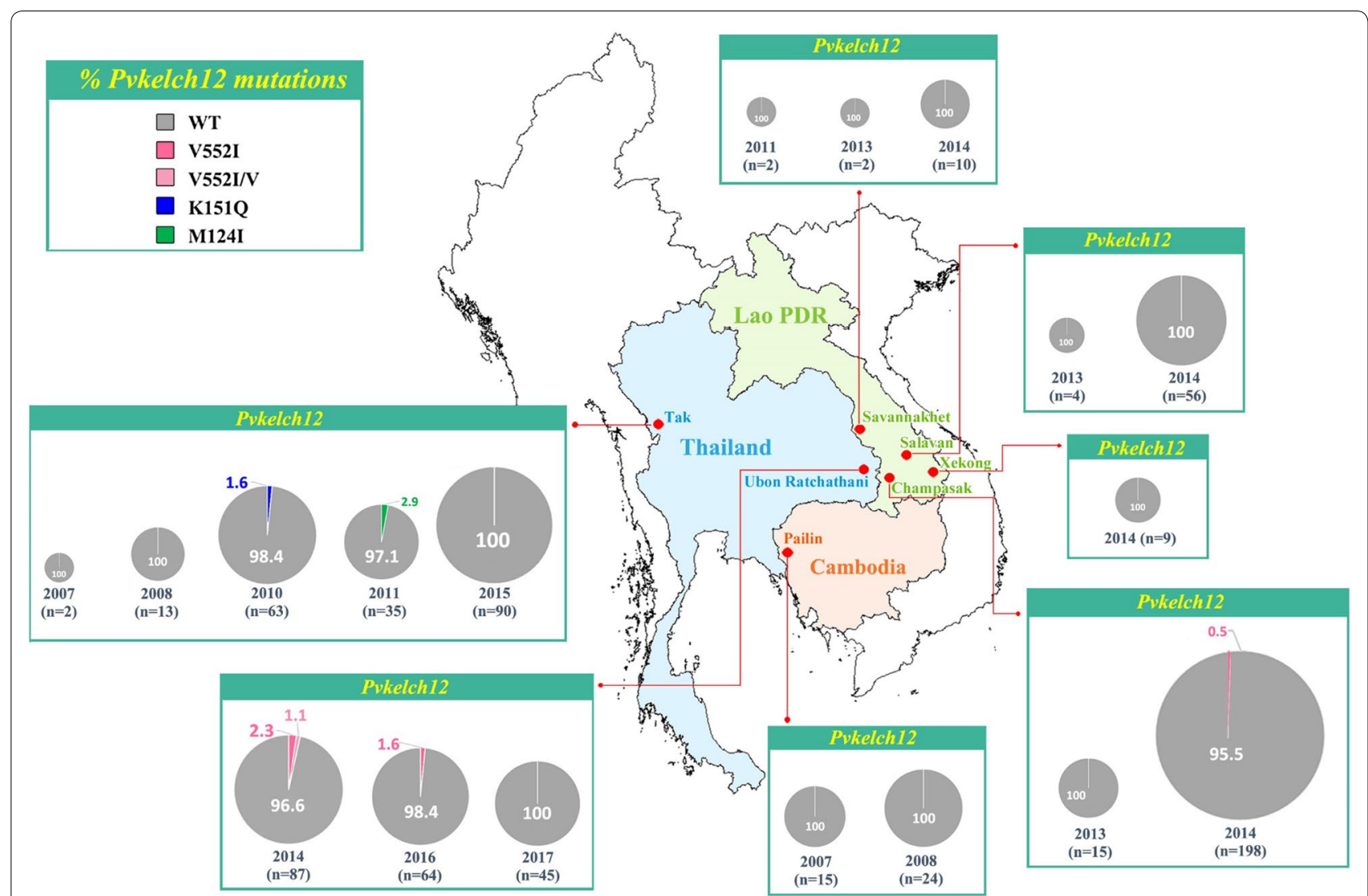

Fig. 2 Frequencies of Pvkelch12 (\%) mutations in Thailand, Lao PDR and Cambodia in 2007-2017 ( $\mathrm{n=734)}$

frequencies in the Pvkelch 12 were not significantly different in regions with ACT as first-line treatment for $P$. vivax (Cambodia) compared to regions with chloroquine as first-line treatment (Thailand and Lao PDR) (Pearson's $\mathrm{X}^{2}$ test, $p=0.38$ ). There was also no association between the frequency of Pvpm4 gene polymorphisms and deployment of DHA-PPQ (Cambodia versus Thailand and Lao PDR) (Pearson's $\chi^{2}$ test, $p=0.50$ ).

\section{Signatures of selection in Pvkelch12 and Pvpm4}

Ratios of nonsynonymous and synonymous mutations were used to identify indicators of selection in Pvkelch12 and Pvpm4. In total, 37/734 (5.1\%) samples contained a SNPs in Pvkelch12; multiple SNPs in a single strain were not observed. Mutations included three nonsynonymous mutations at codons M124I, K151Q and V552I and ten synonymous mutations at codons N57N, I248I, K310K, I332I, T334T, I340I, S350S, D359D, L365L and T401T (Additional file 2). In Pvpm4, 141/305 (46.2\%) samples contained four genetic mutations. This included one nonsynonymous mutation at codon V165I and three synonymous mutations at codon Q74Q, G141G and F364F (Additional file 3). The ratios of Ka/Ks for Pvkelch 12 and
Pvpm4 gene were $<1$ for whole sample set, as well as for parasite from the individual countries (Thailand, Lao PDR and Cambodia). This suggests absence of purifying selection in these genes (Tables 2 and 3).

\section{Pvpm4 copy number variation}

CNV in Pvpm4 was assessed in 141 P. vivax samples from Ubon Ratchathani, Tak (Thailand) and Pailin (Cambodia) obtained between 2008 and 2014. Gene amplification in Pvpm4 was not observed in any sample under investigation (Fig. 3). Details of the assessment are provided in Additional file 4.

\section{Discussion}

Resistance in $P$. falciparum to both artemisinin and piperaquine is now widespread in Cambodia, northeastern Thailand and Southern Lao PDR, and genetic epidemiological studies have identified that this has spread from a single parasite lineage emerging from western Cambodia [15]. In Cambodia, similar drug pressure from DHA-PPQ on the P. vivax as on the $P$. falciparum parasite population can be expected, since DHA-PPQ is also first-line treatment for vivax malaria 


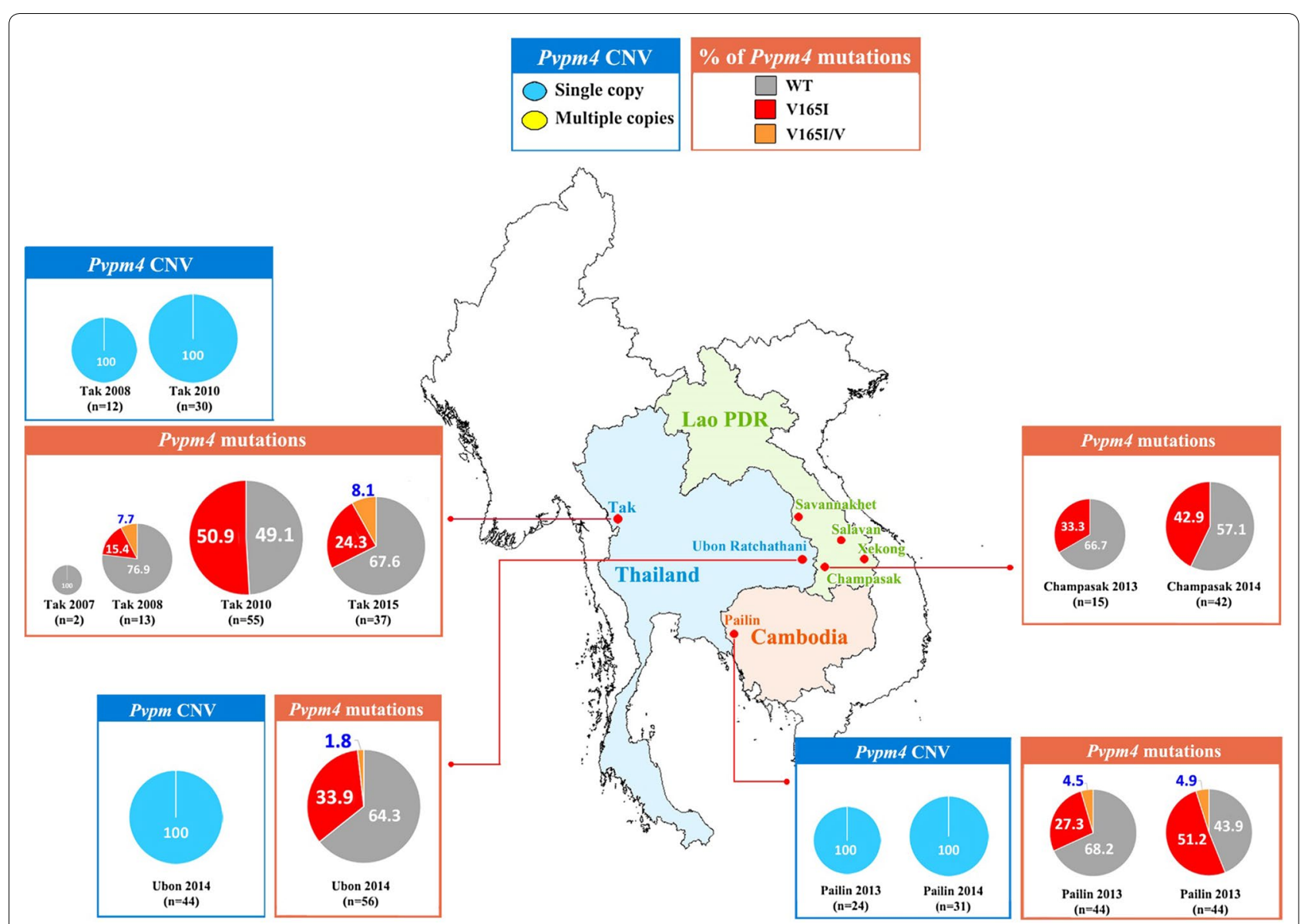

Fig. 3 Distribution of Pvpm4 copy number variations and frequencies of Pvpm4 (\%) mutations in Thailand, Lao PDR and Cambodia in $2007-2017$. Pvpm4 gene amplification was not observed in Ubon Ratchathani, Tak (Thailand) and Pailin (Cambodia) $(n=141)$

in this country [1], and because of the frequent coinfection with the two Plasmodium species [9]. Thus, vigilance is warranted for surveillance of resistance in P. vivax towards these drugs. This surveillance is hampered by the difficulty to perform therapeutic efficacy studies in vivax malaria, since recrudescent infections denoting drug resistance are difficult to distinguish from relapse infections from liver hypnozoites. Also, compared to $P$. falciparum, methods for in vitro drug sensitivity testing for artemisinins and piperaquine are not well established in P. vivax. Molecular markers for drug resistance in $P$. vivax would facilitate surveillance, but no markers have been identified to date. A first step for identifying novel markers would be to study orthologous resistance genes of $P$. falciparum in $P$. vivax, and establish whether mutations in these genes are selected for according to the level of drug pressure. The current study focused on Pvkelch propeller region mutations as a putative marker for artemisinin resistance and Pvpm4 mutations and amplification for piperaquine resistance.
The family of Plasmodium KELCH proteins consist of six KELCH motifs in the propeller domain, linked through a Broad-Complex Tramtrack and Bric-a-Brac/ Pox virus and Zinc finger (BTB/POZ) domain, to the transcription factor/nuclear export subunit protein 2 (Tho2) domain. The kelch gene is highly conserved across different Plasmodium species, with a ratio between nonsynonymous and synonymous mutations (Ka/Ks ratio) around 1 in drug sensitive Plasmodium populations $[22,23]$. SNPs in the propeller regions of Pfkelch 13 are closely linked to the slow clearance $P$. falciparum phenotype denoting artemisinin resistance. Although only single mutation are commonly observed in the propeller region of Pfkelch13 gene, study has shown that multiple mutations are also tolerated [14]. Selection of Pfkelch13 mutations in areas of artemisinin resistance results in a $\mathrm{Ka} / \mathrm{Ks}$ ratio of around $10^{2}$ in countries in the GMS [11,23].

In Africa, nonsynonymous mutations in Pfkelch13 are observed in low frequencies (few percent), without 
Table 2 The ratio of nonsynonymous substitutions per site and synonymous substitutions per site in Pvkelch12 gene

\begin{tabular}{|c|c|c|c|c|c|c|}
\hline Countries & Provinces & Year & Total & Ka & Ks & $\mathrm{Ka} / \mathrm{Ks}^{\mathrm{a}}$ \\
\hline \multirow[t]{8}{*}{ Thailand } & Tak & 2007 & 2 & 0 & 0 & Error \\
\hline & Tak & 2008 & 13 & 0 & 0 & Error \\
\hline & Tak & 2010 & 63 & $3.72 \times 10^{-3}$ & $5.11 \times 10^{-3}$ & 0.728 \\
\hline & Tak & 2011 & 35 & $2.48 \times 10^{-3}$ & $2.55 \times 10^{-3}$ & 0.9703 \\
\hline & Ubon Ratchathani & 2014 & 87 & $2.48 \times 10^{-3}$ & $5.12 \times 10^{-3}$ & 0.4839 \\
\hline & Tak & 2015 & 90 & 0 & $2.55 \times 10^{-3}$ & 0 \\
\hline & Ubon Ratchathani & 2016 & 64 & $2.48 \times 10^{-3}$ & $2.56 \times 10^{-3}$ & 0.9682 \\
\hline & Ubon Ratchathani & 2017 & 45 & $1.24 \times 10^{-3}$ & -1.31815 & -940.45623 \\
\hline \multirow[t]{8}{*}{ Lao PDR } & Savannakhet & 2011 & 2 & 0 & 0 & Error \\
\hline & Champasak & 2013 & 15 & 0 & 0 & Error \\
\hline & Savannakhet & 2013 & 2 & 0 & 0 & Error \\
\hline & Salavan & 2013 & 4 & 0 & 0 & Error \\
\hline & Champasak & 2014 & 198 & $2.48 \times 10^{-3}$ & $5.12 \times 10^{-3}$ & 0.4839 \\
\hline & Savannakhet & 2014 & 10 & $1.24 \times 10^{-3}$ & -1.318159 & -940.45623 \\
\hline & Salavan & 2014 & 56 & $1.24 \times 10^{-3}$ & -1.31815 & -940.45623 \\
\hline & Xekong & 2014 & 9 & 0 & $2.55 \times 10^{-3}$ & 0 \\
\hline \multirow[t]{2}{*}{ Cambodia } & Pailin & 2007 & 15 & 0 & 0 & Error \\
\hline & Pailin & 2008 & 24 & 0 & 0 & Error \\
\hline
\end{tabular}

${ }^{\mathrm{a}} \mathrm{Ka}$ and Ks were estimated by using approximate method, Jukes-Cantor (JC) and Kimuras-two parameter models: https://kakscalculator.herokuapp.com/calculate. action [21]

Table 3 The ratio of nonsynonymous substitutions (Ka) per site and synonymous substitutions (Ks) per site in Pvpm4 gene

\begin{tabular}{llllllll}
\hline Frequence of Pfplasmepsin2 CNV & $\begin{array}{l}\text { Treatment guidelines } \\
\text { for P. falciparum }\end{array}$ & Location & Year & Total Ka & Ks & Ka/Ks \\
& Artesunate-Mefloquine & Thailand (Tak) & $2007-2012$ & 107 & $2.04 \times 10^{-3}$ & $8.22 \times 10^{-3}$ & 0.2488 \\
\hline Pfplasmepsin2 (<5\%) & DHA-PPQ & Thailand (Ubon Ratchathani) & $2012-2015$ & 56 & $2.04 \times 10^{-3}$ & $4.12 \times 10^{-3}$ & 0.4968 \\
& Artemether-lumefantrine & Lao PDR (Champasak) & $2013-2014$ & 57 & $2.04 \times 10^{-3}$ & $4.10 \times 10^{-3}$ & 0.4985 \\
& DHA-PPQ & Cambodia (Pailin) & $2013-2014$ & 85 & $2.04 \times 10^{-3}$ & 0 \\
\hline
\end{tabular}

a $\mathrm{Ka} / \mathrm{Ks}$ ratios of Pvpm4 are grouped by presumed DHA-PPQ drug pressure based on Pfplasmepsin2 amplification prevalence in P. falciparum in the same areas [33, 34]. $\mathrm{Ka}$ and Ks were estimated by using approximate method, Jukes-Cantor (JC) and Kimuras-two parameter models: https://kakscalculator.herokuapp.com/calculate.actio $\mathrm{n}$ [21]

signatures of selection, likely denoting a background mutation rate in the gene [24]. Overall mutation rates for $P$. falciparum are in the range of $1-10 \times 10^{-9}$ per nucleotide site per mitotic division [25-27]. Depending on the fitness loss induced by the mutation, subsequent drug pressure can select for the drug resistant gene, increasing its frequency above background and increasing the $\mathrm{Ka} / \mathrm{Ks}$ ratio [25]. Present study indicates that only $0.95 \%$ of parasites harbored nonsynonymous mutations in Pvkelch12, whereas synonymous mutations were observed in $4.1 \%$ of parasites. This was not different between countries. These findings are in agreement with a previous report showing limited genetic diversity of Pvkelch12 in Southeast Asia [28]. Both the low frequency and the low $\mathrm{Ka} / \mathrm{Ks}$ ratio suggest that there is currently no selection of Pvkelch 12 mutations in $P$. vivax in the study areas in Thailand, Cambodia and Lao PDR, despite the widespread exposure to ACT. Although it is not clearly understood whether Pvkelch 12 plays a role in P. vivax resistance to artemisinins, absence of Pvkelch12 mutations corroborates the absence of clinical resistance to artemisinins in these areas.

Of the Pvkelch12 mutations identified during current study, mutations at position V552I and M124I have been reported previously (Additional file 5); the G581R mutation previously reported from China was not observed in the current study [28-30]. The orthologous Pfkelch13 mutations at positions 555, 126 and 595, have not been 
described in association with artemisinin resistance in falciparum malaria. Vice versa, none of the currently validated artemisinin associated Pfkelch13 mutations have to date been described in the orthologous positions in Pvkelch12 [31].

Plasmepsins I, II, III, and IV in Plasmodium constitute a group of histo-aspartic proteases aiding the hydrolysis of haemoglobin in the plasmodial food vacuole, providing amino acids as food for the erythrocytic stage of $P$. falciparum. Gene amplification of Pfplasmepsin2 and Pfplasmepsin 3 are strongly associated with resistance to piperaquine in falciparum malaria. A potential mechanism is interference with the mechanism of action of this drug, which is inhibiting conversion of toxic haem moieties to nontoxic haemozoin during haemoglobin digestion [32]. Frequencies of CNV in the P. vivax orthologous gene Pvpm4 have not been studied before, and a method for assessing Pvpm4 copy numbers was developed for the purpose of this study. However, Pvpm4 gene amplification was not observed in any of the $P$. vivax samples from Thailand and Cambodia. In contrast, SNPs in Pvpm4 were frequently observed, in particular the nonsynonymous mutation V165I (123/305 or $40.3 \%$ of samples). The mutation has been described previously in $P$. vivax from Malaysia (Sabah) and Thailand [19]. However, it is unlikely that this mutation is related to piperaquine drug resistance, since its frequency was not associated with the level of piperaquine drug pressure (low in Thailand, high in Cambodia) (Table 3).

Although the current study did not show signatures of selection for the identified mutations in Pvkelch12 and Pvpm4, it is warranted to continue monitor these mutations over time and over a larger geographical area, including Vietnam and Myanmar. In addition, future studies on potential molecular markers for resistance in $P$. vivax can include associations with the clinical phenotype (parasite clearance rate and treatment failure) and protein level analysis of Pvkelch12 and Pvpm4.

\section{Conclusions}

Present study assessed mutations in the $P$. vivax orthologous resistance genes Pvkelch12 for artemisinin resistance and Pvpm4 for piperaquine resistance. Although nonsynonymous mutations were observed, the frequency was low, and not higher than synonymous mutations in the same genes. Pvpm4 gene amplification was not observed. Current resistance of $P$. vivax in Thailand, Lao PDR and Cambodia to these drugs is unlikely. Nonetheless, additional observations, validations and analysis of associated clinical data from these malaria endemic zones could further help clarify current findings.

\section{Additional files}

Additional file 1. Accession numbers of nucleotide sequences and sequence IDs of Pvkelch12 and Pvpm4 genes obtained from GenBank database.

Additional file 2. Synonymous mutations in Pvkelch 12 gene Thailand, Lao PDR and Cambodia.

Additional file 3. Synonymous mutations in Pvpm4 gene Thailand, Lao PDR and Cambodia.

Additional file 4. The distribution of Pvpm4 copy number variations in each sample from 3 study sites with geometric means with 95\% confidence interval of Pvpm4 CNV.

Additional file 5. Comparison of Pvkelch 12 mutations of this study to previous publications.

\section{Abbreviations}

Pvkelch 12: P. vivax kelch; Pvpm4: P. vivax plasmepsin4; SNPs: single nucleotide polymorphisms; CNV: copy number variation; qPCR: quantitative real-time PCR.

\section{Authors' contributions}

MI, NJW, and AMD designed the study. JD undertook the laboratory experiment. RT, MM, CN, LS, MD, TP, FN collected the samples. JD, MI, AMD, VBM, NPD, and NJW conducted data analysis. JD wrote the first draft. All authors read and approved the final manuscript.

\section{Author details \\ ${ }^{1}$ Department of Molecular Tropical Medicine and Genetics, Faculty of Tropical Medicine, Mahidol University, Bangkok, Thailand. ${ }^{2}$ Mahidol-Oxford Tropical Medicine Research Unit, Faculty of Tropical Medicine, Mahidol University, Bangkok, Thailand. ${ }^{3}$ Centre for Tropical Medicine, Churchill Hospital, Oxford, UK. ${ }^{4}$ Shoklo Malaria Research Unit, Mae Sot, Faculty of Tropical Medicine, Mahidol University, Mae Sot, Thailand. ${ }^{5}$ Lao-Oxford-Mahosot Hospital-Well- come Trust Research Unit, Mahosot Hospital, Vientiane, Lao People's Demo- cratic Republic. ${ }^{6}$ Institute of Research and Education Development, University of Health Sciences, Vientiane, Lao People's Democratic Republic. ${ }^{7}$ National Centre for Parasitology, Entomology \& Malaria Control, Ministry of Health, Phnom Penh, Cambodia.}

\section{Acknowledgements}

This study was supported by Mahidol University, the Thailand Research Fund, Thailand and the Wellcome Trust of Great Britain.

\section{Competing interests}

The authors declare that they have no competing interests.

\section{Availability of data and materials}

Selected data are provided in Additional files. Additional dataset generated during the current study are available from corresponding author on reasonable request.

\section{Consent for publication \\ Not applicable.}

\section{Ethics approval and consent to participate}

The protocol of this study was reviewed and approved by the ethical review board of Faculty of Tropical Medicine, Mahidol University, Thailand (MUTM 2017-037-01).

\section{Funding}

This work was funded by the Thailand Research Fund, Thailand and the Wellcome Trust of Great Britain.

\section{Publisher's Note}

Springer Nature remains neutral with regard to jurisdictional claims in published maps and institutional affiliations. 
Received: 10 January 2019 Accepted: 26 March 2019

Published online: 02 April 2019

\section{References}

1. WHO. World malaria report 2017. Geneva: World Health Organization. 2017. https://www.who.int/malaria/publications/world-malaria-repor t-2017/report/en/.

2. WHO. World malaria report 2014. Geneva: World Health Organization. 2014: https://www.who.int/malaria/publications/world_malaria_repor t_2014/en/.

3. Amaratunga C, Lim P, Suon S, Sreng S, Mao S, Sopha C, et al. Dihydroartemisinin-piperaquine resistance in Plasmodium falciparum malaria in Cambodia: a multisite prospective cohort study. Lancet Infect Dis. 2016;16:357-65.

4. Lim P, Dek D, Try V, Sreng S, Suon S, Fairhurst RM. Decreasing pfmdr1 copy number suggests that Plasmodium falciparum in Western Cambodia is regaining in vitro susceptibility to mefloquine. Antimicrob Agents Chemother. 2015:59:2934-7.

5. Howes RE, Battle KE, Mendis KN, Smith DL, Cibulskis RE, Baird JK, et al. Global epidemiology of Plasmodium vivax. Am J Trop Med Hyg. 2016;95:15-34.

6. WHO. World malaria report 2015. Geneva: World Health Organization 2015. https://www.who.int/malaria/publications/world-malaria-repor t-2015/en/.

7. Hay SI, Sinka ME, Okara RM, Kabaria CW, Mbithi PM, Tago CC, et al. Developing global maps of the dominant anopheles vectors of human malaria. PLoS Med. 2010;7:e1000209.

8. Mendis K, Sina BJ, Marchesini P, Carter R. The neglected burden of Plasmodium vivax malaria. Am J Trop Med Hyg. 2001;64:97-106.

9. Mayxay M, Pukrittayakamee S, Newton PN, White NJ. Mixed-species malaria infections in humans. Trends Parasitol. 2004:20:233-40.

10. Iwagami M, Keomalaphet S, Khattignavong P, Soundala P, Lorphachan L,

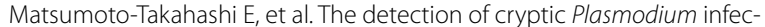
tion among villagers in Attapeu province, Lao PDR. PLoS Negl Trop Dis. 2017;11:e0006148.

11. Ariey F, Witkowski B, Amaratunga C, Beghain J, Langlois AC, Khim N, et al. A molecular marker of artemisinin-resistant Plasmodium falciparum malaria. Nature. 2014:505:50-5.

12. Ashley EA, Dhorda M, Fairhurst RM, Amaratunga C, Lim P, Suon S, et al. Spread of artemisinin resistance in Plasmodium falciparum malaria. N Engl J Med. 2014;371:411-23.

13. Tun KM, Imwong $M$, Lwin KM, Win AA, Hlaing TM, Hlaing T, et al. Spread of artemisinin-resistant Plasmodium falciparum in Myanmar: a cross-sectional survey of the K13 molecular marker. Lancet Infect Dis. 2015;15:415-21.

14. Menard D, Khim N, Beghain J, Adegnika AA, Shafiul-Alam M, Amodu O, et al. A worldwide map of Plasmodium falciparum K13-propeller polymorphisms. N Engl J Med. 2016;374:2453-64.

15. Imwong M, Suwannasin K, Kunasol C, Sutawong K, Mayxay M, Rekol H, et al. The spread of artemisinin-resistant Plasmodium falciparum in the Greater Mekong subregion: a molecular epidemiology observational study. Lancet Infect Dis. 2017;17:491-7.

16. Popovici J, Kao S, Eal L, Bin S, Kim S, Menard D. Reduced polymorphism in the Kelch propeller domain in Plasmodium vivax isolates from Cambodia. Antimicrob Agents Chemother. 2015:59:730-3.

17. Agrawal S, Moser KA, Morton L, Cummings MP, Parihar A, Dwivedi A, et al. Association of a novel mutation in the Plasmodium falciparum chloroquine resistance transporter with decreased piperaquine sensitivity. J Infect Dis. 2017;216:468-76.

18. Witkowski B, Duru V, Khim N, Ross LS, Saintpierre B, Beghain J, et al. A surrogate marker of piperaquine-resistant Plasmodium falciparum malaria: a phenotype-genotype association study. Lancet Infect Dis. 2017;17:174-83.

19. Auburn S, Benavente ED, Miotto O, Pearson RD, Amato R, Grigg MJ, et al. Genomic analysis of a pre-elimination Malaysian Plasmodium vivax population reveals selective pressures and changing transmission dynamics. Nat Commun. 2018;9:2585.

20. Zhang Z, Yu J. Evaluation of six methods for estimating synonymous and nonsynonymous substitution rates. Genomics Proteomics Bioinformatics. 2006;4:173-81.

21. Zhang Z, Li J, Zhao XQ, Wang J, Wong GK, Yu J. KaKs_Calculator: calculating Ka and Ks through model selection and model averaging. Genomics Proteomics Bioinformatics. 2006:4:259-63.

22. Zhang DD, Hannink M. Distinct cysteine residues in Keap1 are required for Keap1-dependent ubiquitination of Nrf2 and for stabilization of Nrf2 by chemopreventive agents and oxidative stress. Mol Cell Biol. 2003:23:8137-51.

23. Miotto O, Amato R, Ashley EA, Maclnnis B, Almagro-Garcia J, Amaratunga C, et al. Genetic architecture of artemisinin-resistant Plasmodium falciparum. Nat Genet. 2015;47:226-34.

24. Ouattara A, Barry AE, Dutta S, Remarque EJ, Beeson JG, Plowe CV. Designing malaria vaccines to circumvent antigen variability. Vaccine. 2015;33:7506-12.

25. Paget-McNicol S, Saul A. Mutation rates in the dihydrofolate reductase gene of Plasmodium falciparum. Parasitology. 2001;122:497-505.

26. Bopp SE, Manary MJ, Bright AT, Johnston GL, Dharia NV, Luna FL, et al. Mitotic evolution of Plasmodium falciparum shows a stable core genome but recombination in antigen families. PLoS Genet. 2013:9:e1003293.

27. Loy DE, Liu W, Li Y, Learn GH, Plenderleith LJ, Sundararaman SA, et al. Out of Africa: origins and evolution of the human malaria parasites Plasmodium falciparum and Plasmodium vivax. Int J Parasitol. 2017:47:87-97.

28. Wang M, Siddiqui FA, Fan Q, Luo E, Cao Y, Cui L. Limited genetic diversity in the PvK12 Kelch protein in Plasmodium vivax isolates from Southeast Asia. Malar J. 2016;15:537.

29. Deng S, Ruan Y, Bai Y, Hu Y, Deng Z, He Y, et al. Genetic diversity of the Pvk12 gene in Plasmodium vivax from the China-Myanmar border area. Malar J. 2016:15:528.

30. Brazeau NF, Hathaway N, Parobek CM, Lin JT, Bailey JA, Lon C, et al. Longitudinal pooled deep sequencing of the Plasmodium vivax K12 kelch gene in Cambodia reveals a lack of selection by artemisinin. Am J Trop Med Hyg. 2016;95:1409-12.

31. WHO. World Health Organization Global Malaria Programme. 2018. http:// apps.who.int/iris/bitstream/handle/10665/274362/WHO-CDS-GMP2018.18-eng.pdf?ua=1.

32. Amato R, Lim P, Miotto $O$, Amaratunga C, Dek D, Pearson RD, et al. Genetic markers associated with dihydroartemisinin-piperaquine failure in Plasmodium falciparum malaria in Cambodia: a genotype-phenotype association study. Lancet Infect Dis. 2017:17:164-73.

33. Suwanarusk R, Russell B, Chavchich M, Chalfein F, Kenangalem E, Kosaisavee $\mathrm{V}$, et al. Chloroquine resistant Plasmodium vivax: in vitro characterisation and association with molecular polymorphisms. PLOS ONE. 2007:2:e1089.

34. Suwanarusk R, Chavchich M, Russell B, Jaidee A, Chalfein F, Barends M, et al. Amplification of pvmdr1 associated with multidrug-resistant Plasmodium vivax J Infect Dis. 2008:198:1558-64. 